Revista Iberoamericana, Vol. LXXXI, Núm. 250, Enero-Marzo 2015, 315-331

\title{
LA INFANCIA EXTRAÑANDO AL DINERO Y AL LENGUAJE EN POTLATCH DE ARTURO CARRERA
}

\author{
POR \\ Ofelia Ros \\ Instituto Caro y Cuervo
}

Todo es acto de fe, fenómeno de crédito o de confianza, de creencia y de autoridad convencional en este texto que puede ser que diga algo esencial a propósito de lo que conecta aquí a la literatura con la creencia, con el crédito y, por lo tanto, con el capital, con la economía $y$, por ende, con la política.

Jacques Derrida, Dar (el) tiempo

La poesía de Arturo Carrera en Potlatch, ocurre extrañando al dinero y al lenguaje a través de una "palabra de la infancia (y no una palabra sobre la infancia)" (158), como apunta el crítico Nicolás Rosa. La misma encarna afectos infantiles sobre el mundo adulto y sus historias con el dinero, sus creencias y sus ritos, pero también sus equívocos, sus incongruencias y sus sin sentido. Recorre los relatos, los mitos, los rumores que componen una narrativa fragmentada y generalizada, en la cual se reproduce y se perpetúa el dinero como objeto rector del intercambio social; pero también bordea los equívocos, los quiebres, las paradojas y los absurdos de esta narrativa. Este doble movimiento es habilitado a través de la mirada de un niño que escucha los diálogos, las conversaciones, de los adultos, incursionando en lo irracional y bizarro, lo no (re) conocido de las narrativas entorno al dinero.

En este artículo analizo la función de la subjetividad infantil en la poesía sobre el dinero de Carrera, avizorando que la misma subraya los quiebres y las fracturas en la sutura de sentido que sostiene el fetichismo del dinero, abriéndonos a las creencias comúnmente no (re)conocidos que perpetúan el dinero como objeto sublime del intercambio. De ésta manera, la mirada infantil nos permite avizorar hábitos de pensamiento y de acción comúnmente pasados por alto, introduciendo una "extrañeza inquietante" que define la experiencia de lo siniestro freudiano: allí donde algo ajeno y extraño es percibido en el seno de lo íntimo y familiar amenazando la estabilidad de lo conocido (Freud, "Lo siniestro" 225). En lo siniestro (unheimlich), Sigmund Freud articula lo heimlich: confiable, propio de la entrañable intimidad del terruño, del bienestar de una satisfacción 
sosegada, de una calma placentera y una protección segura, como las que produce la casa, el recinto cerrado donde se mora, con su antónimo unheimlich: desconocido, ajeno, amenazante y peligroso (222).

La palabra de la infancia abre el campo para el acontecimiento de lo siniestro, en tanto vía regia para establecer un distanciamiento irónico con todo aquello en lo que con pretenciosa certeza aseguramos el mundo de lo propio y conocido. Asimismo, el crítico Nicolás Rosa apunta al referirse a una coautoría de Arturo Carrera y Osvaldo Lamborghini, El palacio de los aplausos: "[t] oda esta literatura aniñada, no una literatura infantil, es una literatura perversa" (158) que desnuda y desestabiliza las creencias sobre las que figuramos nuestra realidad.

A través del análisis freudiano de lo siniestro, el análisis marxista del dinero, y el análisis derrideano del don, trabajo con los poemas del libro que denomino "ritos de iniciación a la lógica del dinero en la infancia". Los mismos recogen un crisol de recuerdos en la intimidad familiar, las fiestas infantiles o la escuela, marcados por un contexto histórico en el que se destacan narrativas sociopolíticas emblemáticas como la del peronismo asociada a las políticas públicas para el ahorro de capital, o la del menemismo y su promesa neoliberal aferrada al cambio de moneda que sostenía la paridad del peso argentino con el dólar. ${ }^{1}$ En los diferentes ámbitos el dinero se hace presente a veces con vistas a la circulación, y otras a la reapropiación y la ganancia; mientras la infancia aparece como resquicio que guarda una familiar extrañeza con las narrativas económicas que la cercan.

En consecuencia, no ofrezco un tratamiento socio-económico del objeto dinero, sino que abordo la economía en su sentido figural, en sus predicados o valores semánticos irreductibles, entre los que se encuentran los valores de casa (oikos) y de ley (nomos). Como lo propone Jacques Derrida, oikos "es la casa, la propiedad, la familia, el hogar, el fuego de dentro" (Dar 16). Mientras que "nomos no significa únicamente la ley en general sino también la ley de distribución (nemein), la ley de la partición y la ley como participación (moira), la parte dada o asignada, la participación" (16). Estudiar los valores de casa y de ley, de partición y repartición, en la poesía sobre el dinero de Carrera, nos conduce a atender a otra tautología señalada por Derrida que "implica ya a lo económico en lo nómico como tal" (16). Por ende, este artículo no aborda el carácter material del dinero, sino "el del material sublime, el de esa otra consistencia

\footnotetext{
Como señala Héctor Schmucler refiriéndose a la historia argentina: "desde que una primera ley, la 1130, estableció el Peso Moneda Nacional hacia 1891" hasta nuestros días, "la unidad monetaria cambió 5 veces de nombre y perdió trece ceros: un Peso actual equivale a diez billones del signo monetario primigenio (10.000.000.000.000)" (8). Cada cambio en el nombre reactivaba la esperanza de soluciones permanentes para la resquebrajada trama social. La pérdida de valor en el salario real y la desocupación que acompañaba la pérdida de ceros en la moneda alentaban, paradójicamente, la ilusión de que el nuevo nacimiento sería definitivo.
}

Revista Iberoamericana, Vol. LXXXI, Núm. 250, Enero-Marzo 2015, 315-331 ISSN 0034-9631 (Impreso) 
'indestructible e inmutable' que persiste más allá de la corrupción del cuerpo físico, ese otro cuerpo del dinero que es como el cadáver de la víctima sadiana que soporta todos los tormentos y sobrevive con su belleza inmaculada" (Slavoj Zizek, El sublime 44).

En palabras de Derrida, podríamos afirmar que la poesía de Potlatch relaciona "la creencia con el crédito y, por lo tanto, con el capital, con la economía y, por ende, con la política" (Dar 32). De esta manera, la misma se inscribe en la tradición literaria Argentina en una compleja relación con el neobarroco.

La poesía de Carrera es, en su comienzo, asociada con el neobarroco, pero sostiene con esta importante tendencia de la poesía Latinoamericana de las últimas décadas una compleja relación. El neobarroco no desarrolla una vinculación directa con el modelo del barroco clásico del Siglo de Oro español; el paradigma no es Góngora o Quevedo sino el cubano José Lezama Lima y su seguidor, también cubano, Severo Sarduy. Éstos desestabilizan el barroco incluyendo el sensualismo de Rubén Darío lo que los acerca a la segunda generación de modernistas hispanos -Delmira Agustini, Julio Herrera y Reissig y Leopoldo Lugones- por lo cual críticos como Jacobo Sefamí, sostienen que el grupo de poetas latinoamericanos al que se denomina neobarrocos podría asimismo denominarse neomodernistas. ${ }^{2}$

En Argentina el neobarroco está en relaciona a la revista Literal y a Nestor Perlonger. A fines de la dictadura militar, cuando asumía el nuevo presidente constitucional Raúl Alfonsín, aparecen en la escena literaria argentina esta nueva corriente literaria. El momento histórico aumentaba la expectativa de una nueva poesía comprometida, un renovado lenguaje realista y militante, cercano a Juan Gelman. Sin embargo, éstos autores no responden a una tradición determinada sino que construyen un programa a partir de una serie de elementos considerados como antitéticos: el Modernismo de Rubén Darío, el vanguardismo de Oliverio Girondo, el simbolismo de Juan L. Ortiz y hasta la lírica sencillista; pero comparten el énfasis en el aspecto fónico del lenguaje, la rebelión en contra de los sistemas centrados y simétricos, el uso de múltiples registros del lenguaje y la intertextualidad.

Prieto ubica la consolidación del neobarroco argentino en la poesía de tres autores: Héctor Piccoli, Arturo Carrera y Néstor Perlongher. ${ }^{3}$ En los tres se observa la fuerte conexión con Lezama y Sarduy. Uno de los sonetos del primer libro de Piccoli se titula Muerte de Narciso, haciendo referencia a la obra de Sarduy; Parque Lezama se titula

2 Por ende, Jacobo Sefamí sostiene que el grupo de poetas latinoamericanos al que se denomina neobarrocos podría asimismo denominarse neomodernistas. Los mismos comparten el énfasis en el aspecto fónico del lenguaje, la rebelión en contra de los sistemas centrados y simétricos, el uso de múltiples registros del lenguaje y la intertextualidad.

3 Como propone Prieto, en la escritura de Piccoli las palabras abandonan su vínculo con el referente y se sostienen unas a otras por su relación de contigüidad dada por el ritmo, la rima (interna y externa), "la aliteración, la sinalefa o el encabalgamiento para producir un efecto sobretodo físico ... una magnificencia puramente verbal que establece un vinculo con las obras de Lugones y de Branchs" (449).

Revista Iberoamericana, Vol. LXXXI, Núm. 250, Enero-Marzo 2015, 315-331 ISSN 0034-9631 (Impreso)

ISSN 2154-4794 (Electrónico) 
el cuarto libro de Perlongher; y Sarduy es el prologuista del primer libro de Carrera, Escrito con un Nictógrafo (1972). En este último Carrera prioriza la materialidad de la palabra con soluciones gráficas e ideogramas. Esta investigación de las posibilidades de gozar con la materialidad de las palabras es característica del neobarroco, en el cual "la sobreabundancia es compatible con el doble o triple sentido, la aliteración y la deformación de los significantes" (7).

Sin embargo, como propone Cecilia Pacella, a partir de Mi padre (1985), el sexto libro de poesía de Carrera, ocurre un giro mediante el cual su poesía "restablece la relación con el referente" (233). Este giro la aleja parcialmente del neobarroco aunque conserva la prodigalidad de imágenes y los juegos con la palabra en su materialidad significante. Para Daniel Freidemberg, el giro se da en su texto Arturo y yo (1984) donde el autor empieza a escribir una especie de novela familiar que se continúa en sus sucesivas publicaciones. Asimismo, Prieto coincidiendo con Edgar Dobry, al apuntar que "la recurrencia temática hacia el mito de la primera infancia le da a la obra de Carrera un carácter orgánico, con personajes y referencias explícitas que saltan de un libro a otro, construyendo una especie de saga narrativa" (449).

La crítica coincide en marcar que desde Escrito con un nictógrafo hasta Oro (1975) su poesía hace manifiesta la ausencia de un significado ulterior y exterior a su propia inscripción. Mientras que desde Arturo y yo en adelante, su poesía se descentra de esta ausencia para abordar un entramado de personajes, recuerdos y lugares que habitan entre la oralidad y la escritura, entre la poesía y la narrativa.

Sin embargo, Nancy Fernández apunta que Arturo y yo consolida un labrado paciente y delicado de la vida cotidiana que no implica "un giro sin retorno o una mudanza poética definitiva" (Experiencia 36) hacia una renovada fe en el lenguaje. Este giro, en que las leyes del texto "parecen ser las de los niños, los sueños y el sexo" (Experiencia 36) se continúa en Animaciones suspendidas (1986) y se consolida en La banda oscura de Alejandro (1996) y Children's corner (1998), pero “comienza, sin embargo, a delinearse en uno de sus textos más neobarroco, a saber, La partera canta (1982)" (Experiencia 36). Nancy rescata una constante que otorga carácter orgánico a la obra: "la experiencia de lo real, el saber sobre la vida y sobre el mundo afirmado y recogido en el espacio lábil de la poesía" (Experiencia 15). La autora no define lo real; pero si entendemos lo real con César Aira, como "la experiencia irreducible al pensamiento, lo previo, lo inevitable y a la vez lo inalcanzable" ("La innovación" 22), y con Jacques Lacan, como aquello que no se manifiesta únicamente cómo vacío sino también como repetición ( Los cuatro xi), lo real no cesa de no inscribirse en la poesía de Carrera, y a su vez, no cesa de retornar en la historia mínima, oculto en la repetición cotidiana, en lo imperceptible de tan familiar, en lo invisible de tan conocido.

De esta forma, como propone Juan Duchesne en el prólogo a la Antología de la obra y la crítica de Carrera, éste "reduce la sociedad entera a una familia de genealogías",

Revista Iberoamericana, Vol. LXXXI, Núm. 250, Enero-Marzo 2015, 315-331 ISSN 0034-9631 (Impreso)

ISSN 2154-4794 (Electrónico) 
"redimensiona la vanguardia cosmopolita en provincia inverosímil, transmuta la consabida transgresión en piedad por cada nanosegundo del amor familiar". Así también expresa en el prólogo de Potlatch el mismo Carrera que éste es una continuación de sus libros anteriores, "donde las series tíos, primos, abuelos, padres, abuelas, tías, primas, pequeñas parcas [...] parecían carecer todavía de esa amalgama de representaciones que une, liga los órdenes que simulan la gran indiferencia en la infancia. Y ese pega-pega es el dinero" (9) Sin embargo, esa amalgama de representaciones está constantemente fracturada por el "apagón de sentido" que atañe al dinero en la infancia, donde es sólo el "eco de un valor", donde "todavía no sabíamos bien lo que era" (9). En Potlatch la disrupción de las leyes del lenguaje ocurre en tensión con la estructura de sentido a la que pertenece la palabra. Los traspiés en el discurso, los sin sentido, las contradicciones y las incoherencias de los hábitos en torno al dinero son emblemáticos de esta tensión, ya que plantean conexiones entre lo que (re)conocemos y lo que no (re)conocemos en la relación con el dinero de toda una época.

Cuando a mi hermanita Lara se le cayó... creo que era el primer diente que se le había caído o uno de los primeros, y entonces todos hablábamos de que iba a venir el ratón Pérez y que cómo hacía, y que el Ratón Pérez se iba a llevar el dientito que iba a poner debajo de la almohada y qué se yo, que le iba a dejar la monedita... Y entonces Lara estuvo un rato reflexionando y nos dice: "ay, yo no quiero que ese animal peludo se suba arriba de mi cama" (Carrera 69).

Estos ritos destacan la oscilación del niño que cercado por relatos y narraciones que lo introducen a reconocer el valor del dinero, aún no muestra un éxito rotundo en su iniciación; concentrados en el intercambio diente-moneda nadie reparaba en el animal que lo ejecuta hasta que Lara lo presentifica, y su aspecto peludo cobra valor en la escena. El comentario de Lara desnaturaliza la práctica del "ratón de los dientes de leche", dejando en evidencia su carácter de rito. Las prácticas de intercambio se llevan adelante más allá de que se entiendan o no, de que se comprendan o no. "Te decían que iba a venir el ratoncito... era muy sencillo porque te dejaban algo de plata y vos te ibas a comprar algo" (68).

Asimismo, este grupo de poemas señala que la dualidad entre la realidad fáctica de la práctica de intercambio, entendida como externa, y la experiencia subjetiva de la creencia, entendida como interna, se demuestra inútil para abordar estos ritos de iniciación. En ellos no podemos pensar la creencia como algo meramente subjetivo e interno, sino encarnada en prácticas sociales en las que se reproduce y se perpetúa. A su vez, la práctica social no se presenta como algo meramente externo y objetivo, sino que se entrama en una narrativa junto con creencias y fantasías, como lo expone el siguiente fragmento: "[e]ntonces yo lo ponía en una servilleta de papel, bien envueltito, porque me habían dicho que el diente no podía ir a cualquier lugar, que iba a lugares mágicos y que

Revista Iberoamericana, Vol. LXXXI, Núm. 250, Enero-Marzo 2015, 315-331 ISSN 0034-9631 (Impreso)

ISSN 2154-4794 (Electrónico) 
después el ratón con todos los dientes que juntaba se iba a hacer un castillo de la puta madre" (69). Al igual que el comentario de Lara sobre el animal peludo que le dejaría la moneda, en el fragmento anterior la "palabra que proviene de la infancia" sacude la lógica del relato que rige el intercambio (Rosa 158). La misma desestabiliza la narrativa con una ocurrencia irrisoria, con un traspiés donde la lógica económica no cierra del todo: ¿para qué podría querer este Pérez tantos dientes?, ¿por qué un animal peludo ejecutaba la transacción? Como si se tratara de un resbalón en piso inadvertidamente mojado la "palabra de la infancia" subraya un sin-sentido en el hábito y en la creencia que mueve a la risa.

Los ritos evocados en la poesía de Potlatch se componen de una combinación de elementos del mundo infantil con elementos de la economía del mundo adulto. En esta combinación la poesía se toca con la oralidad para señalar un afuera de las fronteras de la racionalidad del lenguaje en la infancia, donde la misma ocurre extrañando a la lógica del intercambio; pero donde a su vez, la lógica del intercambio la asimila y la transforma, como lo muestra la siguiente conversación ente padre e hija esperando la llegada de los Reyes Magos:

"¿Qué me van a traer -pá- los reyes?;/ ¿me van a traer esos bsbss que les pedí?" -y/ me lo decía al oído, poniendo su manita en el contorno de mi oreja como para volver más audible el enigma,/... cuando otra vez la vocecita nombra/ todo el supremo intercambio:/ ¿qué les daré yo, pá? ¿Pasto?" (117). ${ }^{4}$

La infancia es cercada por una narrativa multitudinaria y fragmentada donde todo se paga o simplemente se debe. Paradójicamente, Carrera destaca el apagón de sentido que atañe al dinero en la infancia justo en el punto en el que el niño es cercado por los relatos y las prácticas que lo introducen al intercambio económico. En este último rige la materialidad abstracta y sublime del dinero, determinando obligaciones y derechos en un orden social que reproduce y perpetúa relaciones de dominio y sometimiento. La lógica del intercambio económico invade el mundo de los ratones, los castillos, los reyes y los álbumes de figuritas; pero, ¿se trata de la misma lógica?, ¿la lógica del dinero como mercancía es la misma que la lógica del dinero como capital?

Marx propone la existencia de dos lógicas diferentes en el uso del dinero. Una de ellas atañe al dinero como mercancía que adviene en el contexto de la circulación simple de las mismas: el dinero como equivalencia generalizada, nombre monetario de las todas las mercancías. La otra pertenece al contexto de la circulación del dinero como capital. Para el autor, la historia moderna del capital comienza con las características que adquiere el mercado en el siglo xvI, las cuales conducen a un cambio en la finalidad y la lógica del intercambio.

4 Resaltado en el original, de aquí en adelante se especificará únicamente cuando no lo sea.

Revista Iberoamericana, Vol. LXXXI, Núm. 250, Enero-Marzo 2015, 315-331 ISSN 0034-9631 (Impreso)

ISSN 2154-4794 (Electrónico) 
En el dinero como mercancía, prima la transformación de la mercancía en dinero y nuevamente su transformación en mercancía. De esta forma, si partimos de un metro de tela y lo cambiamos por dinero, es porque la finalidad es comprar un vestido o un kilo de arroz. La fórmula que obtenemos entonces es "mercancía-dinero-mercancía", y su lógica es "vender para comprar" una mercancía distinta a la que se tenía en un principio (Marx 88). Por el contrario, en la circulación del dinero como capital, la fórmula es "dinero-mercancía-dinero", y la lógica es "comprar para vender" (87). La fórmula cierra el círculo ya que la finalidad es llegar al mismo material del cual se partió: el dinero. Según Marx "cualquier dinero que realiza ese movimiento, conviértase en capital" (94). En esta lógica la finalidad del comprador es recobrar su dinero como vendedor. Este intercambio conforma un movimiento circular que "termina de manera análoga como empieza: por el dinero" (95).

Desde otra perspectiva, Jacques Derrida señala en su libro Dar (el) tiempo, que los predicados y los valores semánticos de la palabra economía implican una forma de intercambio basada en la figura del círculo. ${ }^{5}$

La figura del círculo se encuentra en el centro de toda la problemática de la oikonomia, así como en el de todo el campo económico: intercambio circular, circulación de los bienes, de los productos, de los signos monetarios o de las mercancías, amortización de los gastos, ganancias, sustitución de los valores de uso y de los valores de cambio ... Este motivo de la circulación puede dar a pensar que la ley de la economía es el retorno - circular- al punto de partida, al origen (Derrida 16).

El autor destaca la circularidad del movimiento económico, en el cual la economía tomaría siempre el camino de Ulises en una estructura odiseica que destaca el retorno al origen del que se partió. Este retorno que parte del dinero y llega al dinero encuentra su única razón de ser en una diferencia cuantitativa al final de la ecuación, o sea, en la ganancia y la acumulación de dinero. Como señala Marx, el movimiento del dinero como capital sólo tiene razón de ser en la diferencia cuantitativa de las dos sumas de dinero, en busca de un excedente, un acrecentamiento al que denomina plusvalía. ${ }^{6}$

Sin embargo, no hay nada en la abstracción del dinero como equivalencia universal de las mercancías que implique el movimiento circular del dinero como capital. En los "ritos de iniciación al dinero en la infancia", que hemos recorrido a través de la poesía de Potlatch, el dinero tiene la forma de mercancía. Es un elemento más de la cadena de

5 Kate Jenckes relaciona Potlatch con Dar (el) tiempo en su trabajo inédito presentado en la Conferencia de Hispanic Studies University of Aberdeen 3.23.07.

6 Marx propone en el Capítulo V, "Las contradicciones de la formula general del capital", que aún admitiendo el cambio de valores desiguales, la circulación de la mercancía no genera capital. La plusvalía no puede proceder en ningún caso de la circulación del dinero. Es la fuerza de trabajo entendida como mercancía que explica el origen del capital como trabajo impago.

Revista Iberoamericana, Vol. LXXXI, Núm. 250, Enero-Marzo 2015, 315-331 ISSN 0034-9631 (Impreso)

ISSN 2154-4794 (Electrónico) 
intercambios: dinero, diente, caramelos, pasto, regalo, con el brillo de aquello que puede ser cambiado por cualquier otra cosa. Por el contrario, en los poemas que trabajaremos a continuación se enfatiza el dinero como capital económico que prioriza el retorno al sí mismo, la ganancia y la acumulación. Varios de ellos tienen como eje los programas de ahorro estatales para la niñez, en los que la partición y repartición, la administración de los bienes, pasa a ser función del Estado.

La sección "Ahorro" de Potlatch se focaliza en narrativas que se enseñan y se aprenden en el ámbito escolar de los años cincuenta en la Argentina. El primer poema del libro culmina con el slogan de los programas de ahorro estatal de La Caja Nacional de Ahorro Postal (CNAP): “iAhorra!/ La Caja Nacional de Ahorro Postal espera tu depósito./ ¡Hazlo ahora que puedes! Te lo devolverá cuando más lo necesites” (13). El mismo asegura el afianzamiento de un porvenir sin necesidad económica gracias al ahorro: el retorno sin riesgos del dinero en el momento necesitado. La CNAP se crea el 29 de septiembre de 1914 mediante la ley 9.527, y su programa de ahorro alcanza alta aceptación y popularidad social en el año 1947 al adherir un seguro colectivo para el personal del Estado.?

Carrera evoca la práctica de ahorro instaurada a través de las escuelas mediante relatos que funcionan como trozos de memoria, donde se mezclan las anécdotas personales y los fragmentos de historia en una pluralidad de voces a medio camino entre la oralidad y la escritura, como lo muestra el siguiente poema:

\begin{abstract}
Nosotros le comprábamos las estampitas a la maestra para ahorrar. Teníamos un boletín de la Caja Nacional de Ahorro Postal. Entonces, ahí pegábamos todo como figuritas. Cuando teníamos el boletín lleno íbamos al Correo con la libreta de ahorro y el boletín de ahorro. Entonces, mostrábamos el boletín, nos sellaban la libreta de ahorro y allí ponían el importe y se quedaban con el boletín lleno de estampillas (124).
\end{abstract}

A los ojos del niño, el boletín y las estampitas se asemejan a un álbum en el que se coleccionan figuritas. Sin embargo, la libreta de ahorro - donde el empelado del Correo escribe el importe, pone el sello y se queda a cambio con el boletín- no pertenece al ámbito del juego, es de otro orden normativo análogo al de la libreta de notas donde la maestra escribe su evaluación.

No son pocos los niños que diariamente gastan en golosinas o en juguetes veinte centavos ... Si en lugar de habituarse a gastar inútilmente esa cantidad, tomasen la costumbre de depositarla religiosamente en la CAJA NACIONAL DE AHORRO POSTAL, al

7 La CNAP sufre una serie de transformaciones a partir de los años 70. En el año 73 cambia su nombre a Caja Nacional de Ahorro y Seguro, y en el 91 se declara sujeta a privatización, la cual culmina en el año 93 al aprobarse las cuatro nuevas sociedades que la sustituyen: Caja de Ahorro y Seguro S.A., Banco Caja de Ahorro S.A., Caja de Seguros S.A. y Caja de Seguros de Vida S.A.

Revista Iberoamericana, Vol. LXXXI, Núm. 250, Enero-Marzo 2015, 315-331 ISSN 0034-9631 (Impreso)

ISSN 2154-4794 (Electrónico) 
mismo tiempo que se libraban de contraer hábitos de disipación y se acostumbraban a disciplinar su voluntad y a dominarse a si mismos -beneficios inapreciables- se encontrarían con que insensiblemente, al cabo de cierto número de años, eran poseedores de un capitalito [...]. REFLEXIONEN LOS NINOS Y SOBRE TODO REFLEXIONENSUS PADRES (103).

El poema hace visible el carácter de mandato, el deber moral con el que se introduce al niño en la práctica del ahorro. Asimismo, ésta sienta las bases para que la finalidad que gobierne la acción sea la ganancia, el logro de una diferencia cuantitativa de dinero al final del camino: un capitalito que lo valide.

Por otro lado, en esta misma sección, Carrera intercala relatos sobre el ahorro en el ámbito doméstico. A diferencia de los anteriores, en éstos se destaca la heterogeneidad en la práctica y en los fines del ahorro. Por ejemplo, el uso de distintos tipos de alcancía: la lata con una hendidura en la tapa, el chanchito de porcelana, los jarros de vidrio y los monedómetros. Esta variedad de formas de ahorro se combina con varias opciones a la hora de gastar las monedas, que se transforman en chocolates, revistas y adornos baratos para la repisa de los abuelos. Por el contrario, en el ámbito escolar se destaca la homogenización de la práctica de ahorro, haciendo énfasis en depositar religiosamente, disciplinar la voluntad y dominarse a sí mismos para ser con el tiempo poseedores de un capitalito.

Por otro lado, los poemas subrayan el énfasis de las narrativas oficiales en asimilar el ahorro en el ámbito doméstico con en el ahorro en el ámbito estatal, con el fin de promover éste último. Por ejemplo, el símbolo de la Caja de Ahorro que se pegaba en los boletines:

[e]ra una nena sentada, con un vestidito, con dos trenzas recogidas alrededor de la oreja, y tenía en las manos, es decir como en el regazo, una alcancía redonda de barro con una ranura ... Y de un lado decía: 'infancia previsora', y del otro: 'vejez tranquila' ¡Que mentira! ¡Que horror!” (127)

El logo apunta a la asociación entre el ahorro en el ámbito doméstico, emblematizado en la alcancía y el ahorro en el ámbito institucional. Pero esta asociación termina en un horror que la desmiente y acusa la falsedad de la promesa de ganancia asegurada por el discurso económico estatal. De igual forma, otro de los poemas expresa: "Y así íbamos ahorrando, que era muy poco. Y después eso nunca lo retiramos porque con las devaluaciones fue nada" (125). Por ende, no faltan en estos relatos los traspiés del discurso oficial en la fractura de la ilusión del retorno prometida en el ahorro.

Varios de los poemas que refieren al ahorro señalan un quiebre en el discurso político. Los cuatro primeros poemas del libro, por ejemplo, tienen como fecha el año 1954, finales de la segunda presidencia de Juan Domingo Perón (1952-1955). Los mismos destacan

Revista Iberoamericana, Vol. LXXXI, Núm. 250, Enero-Marzo 2015, 315-331 ISSN 0034-9631 (Impreso)

ISSN 2154-4794 (Electrónico) 
la construcción discursiva del peronismo en un tiempo en que los acontecimientos sociales no hacían otra cosa más que resquebrajarla. En 1954, la administración estatal del Peronismo enfrenta graves problemas económicos acompañados de conflictos sociales y políticos. Por un lado, el gobierno firmó con una filial de la compañía de petróleo Standard Oil de California un contrato de explotación de 40 mil hectáreas en la provincia de Santa Cruz, cediéndole amplios derechos. Como propone el historiador L.A. Romero: "Se trataba de una medida que desafiaba convicciones hondamente arraigadas -e incluso una disposición de la Constitución de 1949- que suscitó un amplio debate público" (124). Esto generó desacuerdos y enemistades debilitando aún más la autoridad política del peronismo. El líder del partido radical de izquierda, Arturo Frondizi, declaró el acuerdo como una decisión anti patriótica, y el diputado John William Cooke fue la voz disidente más fuerte dentro del peronismo. El acuerdo ocurrió en el marco de una visible reconciliación con los Estados Unidos, donde la concurrencia de capitales extranjeros era el tema central de debate de las políticas económicas en la época. Los comienzos de la crisis económica del año 54 fueron acompañados por manifestaciones de disconformidad entre dos de los principales apoyos del régimen peronista: los sindicatos y el ejército. ${ }^{8}$ La solución "implicó un avance en el camino del autoritarismo ... prisión a los dirigentes rebeldes y movilización militar a los obreros en huelga" (L.A. Romero 124). En suma, la fecha que Carrera escoge para los primeros poemas de Potlatch marca un momento de quiebre, una fisura en la ilusión de consenso y pacto social entorno al peronismo, asociada a la ruptura de la promesa de prosperidad económica.

Porúltimo, cabe destacar que en varios de estos poemas -que refieren explícitamente al año 1954, la fecha del resquebrajamiento del segundo gobierno peronista- si bien no mencionan a Perón mencionan repetidamente a Eva Duarte de Perón, popularmente conocida como Evita. "Lidia Muñón soñó que Evita le regalaba una muñeca. / Le contó a ella su sueño en una carta y a fin de año tuvo la muñeca soñada. / Desde entonces Lidia es muy feliz" (Carrera, Potlatch 14). El poema destaca la ilusión de una comunicación directa con el poder político a través de las miles de cartas con demandas que recibía la fundación. En la carta de un niño, o sea, en la subjetividad infantil a diferencia de la subjetividad adulta, la demanda es más fácilmente concretizable y materializable en un objeto, en este caso una muñeca, pudiendo así ser satisfecha.

Otro poema expresa: "[t]renes felices de niños que ríen y cantan recorren el país. / Es el milagro de la fundación Eva Perón" (15). La figura del niño en estos poemas deviene metáfora, casi demasiado literal, del paternalismo peronista con las clases más bajas, y subraya con cierta ironía la infantilización de las mismas. Por otro lado, la labor de Eva con las clases más bajas y desprotegidas socialmente a través de la Fundación,

8 Ver al respecto Perón y su tiempo de Félix Luna y Argentina de Perón a Lanusse, 1943-1973 del mismo autor.

Revista Iberoamericana, Vol. LXXXI, Núm. 250, Enero-Marzo 2015, 315-331 ISSN 0034-9631 (Impreso)

ISSN 2154-4794 (Electrónico) 
al igual que con el gremio de trabajadores, posibilitaron la ilusión de representatividad de las mayorías que revistió el primer período presidencial de Perón (1949-1952). Las promesas de prosperidad social y económica fueron sostenidas por políticas sociales, avances en las técnicas de producción y en los medios de industrialización durante el primer peronismo. Sin embargo, la coyuntura mundial no era la misma hacia finales del período, y las promesas se vieron violentamente desmentidas por la devaluación de la moneda que repercutía negativamente en el salario real y las luchas de poder que agudizaban el conflicto político.

Las sucesivas crisis económicas de la historia argentina se acompañan de cambios en el nombre de la moneda y su consecuente pérdida de ceros. Otro grupo de poemas de Potlatch hace hincapié en el asombro, la extrañeza y el desconcierto de un niño ante las leyes que implementaban estos cambios.

\begin{abstract}
Sí, recuerdo escuchar los comentarios de mis viejos, con alguien, de esto de que iban a cambiar la moneda, que se iban a correr dos o tres ceros, no me acuerdo los detalles, y una sensación de mucha extrañeza, como si se hubiera perdido el valor estable de la moneda... Extrañeza mía, que era tan chica, frente a la extrañeza medio ininteligible para mí de ellos (35).
\end{abstract}

Esta extrañeza, este no entender que se permite el niño desde su lugar de niño, contrasta con la ininteligibilidad de la extrañeza del adulto; como si el cambio a éste último no lo sorprendiera del todo. En otras palabras, el poema subraya el "como si" mediante el cual el adulto parecería estar al tanto de la fractura en la que trastabilla el carácter sublime del dinero, pero aún así, no renuncia a su mascarada ideológica. $\mathrm{Al}$ tanto de la falsedad de sostener el carácter sublime del dinero, como entidad que cobra valor por fuera del campo de los conflictos sociales con una ley que regula sus ceros, aún así, la población se aferraba una vez más a la ilusión de que el cambio de moneda traería un cambio social y económico. La extrañeza ininteligible que subraya la niña del poema nos remite al planteo de Zizek sobre la subjetividad contemporánea quien, citando la fórmula de Peter Sloterdijk, afirma: "ellos saben muy bien lo que hacen, pero aún así lo hacen" (57). ${ }^{9}$ En consecuencia, la poesía de Potlatch a través de la subjetividad infantil, no señala la máscara ideológica en la que el dinero sustenta su forma de objeto sublime; señala que el adulto medio reconoce ésta máscara ideológica pero todavía encuentra razones para conservarla.

9 La fórmula de Peter Sloterdijk da un giro a la fórmula en la que Marx explica el fetichismo de la mercancía como falsa consciencia ideológica de las condiciones de la realidad: "los hombres no relacionan entre sí los productos de su trabajo como valores porque estos objetos les parezcan envolturas simplemente materiales de un trabajo humano igual. Es al revés. Al equiparar unos con otros en el cambio, como valores, sus diversos productos, lo que hacen es equiparar entre sí sus diversos trabajos, como modalidad de trabajo humano. No lo saben, pero lo hacen" (Marx 64).

Revista Iberoamericana, Vol. LXXXI, Núm. 250, Enero-Marzo 2015, 315-331 ISSN 0034-9631 (Impreso)

ISSN 2154-4794 (Electrónico) 
El siguiente poema hace referencia a un cambio de moneda emblemático en la década de los 90, en el cual se pasó de la línea Austral a la línea Peso Convertible.

Con manu militari debió escribir esto. Reíte, Él tenía que escribir esto ... escribía estas cosas como discursos, pero no son discursos, vos me entendés. Son órdenes. Lo tenía que hacer. Te leo: La línea monetaria vigente en la República Argentina es la línea PESO CONVERTIBLE (Decreto del Poder Ejecutivo Nro. 2128 -acá está corregido ¿ves?-, del 10 de octubre de 1991 y el Artículo 12 de la Ley de Convertibilidad Nro. 23928 del 27 de marzo de 1991). Todo esto ahora es un redisparate. Escuchá: Todas las lineas anteriores se encuentran desmonetizadas y no se canjean. La relación entre la actual línea y su predecesora, la línea Austral, fue de 1 peso $=10000$ Australes (Carrera, Potlatch 35).

La medida fue impuesta por Domingo Cavallo, ministro de Economía de Carlos Saúl Menem. Ésta determinaba que la mayoría de la base monetaria debía estar respaldada por oro y divisas; pero aceptaba que un porcentaje estuviera respaldada por bonos de deuda del Estado Nacional, valuados a su precio de mercado. Según Cavallo, se trataba de un movimiento económico que permitiría implementar políticas monetarias mediante operaciones de mercado abierto. Sin embargo, las expresiones "con manu militari", "son órdenes" y "lo tenía que hacer" nos remiten a la última dictadura militar (1976-83), con lo cual el poema marca cierta continuidad en las políticas económicas de ambos períodos. En la década de los 90 las políticas económicas nacionales se dirimían en organismos de crédito internacionales como el FMI o el BID. Éstos delineaban políticas neoliberales para la región que seguían el camino zanjado por las políticas económicas implantadas durante la última dictadura militar. ${ }^{10}$ Éstas agudizaron el desempleo y la desigualdad, resultando en la profunda crisis social y política que explotó en el colapso económico de fines del 2001.

En el mencionado cambio de moneda, como en los anteriores, se creyó en la ley a sabiendas del sórdido absurdo que encerraba, del "redisparate" que le devolvió el paso del tiempo; se actuó como si el cambio de nombre y de ceros materializara un cambio en la riqueza económica del país, en la partición y en la repartición de la misma. El recuerdo de la infancia desnaturaliza el vínculo del dinero con la ley y de ésta con la autoridad. Así como lo discute Derrida en Fuerza de ley, donde afirma que el fundamento místico de la autoridad consiste en que "[l]a autoridad de las leyes sólo reposa sobre el crédito que se les da. Se cree en ellas, ése es su único fundamento ontológico o racional” (30). No obedecemos la ley porque es racionalmente justa o buena, sino simplemente porque es ley. Este círculo vicioso en el cual la autoridad se perpetúa a sí misma, sostiene la ley

${ }_{10}$ Las políticas económicas neoliberales imponían, a grandes rasgos, una reducción del gasto público, un aumento de la libertad de mercado y flexibilización del contrato laboral a los países en vías de desarrollo mediante los organismos de crédito.

Revista Iberoamericana, Vol. LXXXI, Núm. 250, Enero-Marzo 2015, 315-331 ISSN 0034-9631 (Impreso)

ISSN 2154-4794 (Electrónico) 
en una posición de exterioridad, de no-relación con la red social. El poema destaca el círculo vicioso de autoridad en el que se sostienen el dinero y subraya mediante la mirada del niño la naturalización con la que el adulto asume la ley. La ausencia de extrañeza ante la medida no implica su justicia o su racionalidad, por el contrario, subraya la naturalización, la invisibilización de un "redisparate". A pesar de la ineficiencia de las políticas económicas que acompañaron los sucesivos cambios de moneda, se mantenía la ilusión que éste fuera el definitivo, aferrados a la promesa en su mascarada ideológica. Una vez más, se actuó como si el cambio de nombre y de ceros del dinero representara un cambio en su valor, y que esto pudiera ocurrir al margen de un cambio en la decreciente producción económica del país y su creciente deuda externa.

Sin embargo, Potlatch no apunta a hacer caer la ilusión universal entorno al dinero, lo cual sería demasiado ilusorio, sino que explora cómo la misma se reproduce y se perpetúa en una narración de narraciones. En esta línea de pensamiento, Carrera propone en el prólogo a Potlatch que "la palabra y el dinero son forzamientos, inequidades metafóricas" (9). La palabra implica una abstracción de pensamiento en la que ciertas cualidades de un determinado objeto son obliteradas en pos de una asimilación a los de su clase. ${ }^{11}$ Todo acto de lenguaje implica un movimiento metafórico mediante el cual se homogeneizan cosas diferentes.

Asimismo, este forzamiento metafórico es fundamental al acto de intercambio mediado por el dinero. La mercancía reduce su valor a su precio, cegando sus particularidades concretas, su valor de uso. El valor aparece en relación a otras mercancías; el precio, nombre monetario de las mercancías, no representa una cualidad natural de los objetos sino una cualidad de origen exclusivamente social: el valor de cambio. En palabras de Marx "el valor no lleva escrito en la frente lo que es. Lejos de ello, convierte a todos los productos del trabajo en jeroglíficos sociales, pues es evidente que el concebir los objetos útiles como valores es obra social suyos, ni más ni menos que el lenguaje". Ponerle precio a un objeto es, en última instancia, obra del lenguaje que convierte a todos los productos del trabajo humano en "jeroglíficos sociales" a través de su valor de cambio. Por ende, el lenguaje es la matriz del forzamiento metafórico emblemático del dinero. En el lenguaje hay homogeneización, hay división y jerarquización, hay relación y valor. "En cuanto hay ley, hay partición: en cuanto hay nomia hay economía" (Derrida, Dar 16).

Sin embargo, si bien la nomia está en la matriz que habilita el uso del dinero, ésta no implica necesariamente la lógica del dinero como capital. La palabra de la infancia en

${ }^{11}$ El nombre agrupa en un conjunto ciertas heterogeneidades de los objetos y las cosas mediante una cobertura lógica. Como lo ejemplifica Borges a través de Funes el memorioso: "el símbolo genérico perro abarcara tantos individuos dispares de diversos tamaños y diversa forma". A Funes "le molestaba que el perro de las tres y catorce (visto de perfil) tuviera el mismo nombre que el perro de las tres y cuarto (visto de frente)" (489).

Revista Iberoamericana, Vol. LXXXI, Núm. 250, Enero-Marzo 2015, 315-331 ISSN 0034-9631 (Impreso)

ISSN 2154-4794 (Electrónico) 
la poesía de Carrera introduce una "extrañeza inquietante" en la lógica del dinero como capital, es ajena a la acumulación, a la ganancia y al afán de poseer un futuro capitalito (Freud, "Lo siniestro" 225). Por el contrario, la infancia subraya la contingencia y la singularidad, lo imprevisible e incalculable de cada acto de intercambio. Convoca el acontecimiento de don introduciendo una "extrañeza inquietante" en la gramática de la situación de intercambio (Freud, "Lo siniestro" 225).

¿qué es un "don" -ahora- si no el restablecimiento de su propio enigma, de su no definición, del consentimiento de una voluntad de entrega y de intercambios a veces ruin casi siempre imposible en relación a objetos que se truecan, que se dan, que se prestan, que se pierden, que se fingen como entregados, desaparecidos o consumidos en un flujo espiritual desgarrador y decisivo entre donatarios y donadores? (Carrera 9)

En uno de los epílogos de Potlatch, Carrera toma un fragmento de Historial de un libro del poeta español Luis Cernuda emblemático de la inocencia y la gratuidad de la infancia acontecen en la estructura estable, histórica y repetible de toda economía. ${ }^{12}$

Alguna vez me contaron en la casa familiar, en Sevilla, cómo durante la fiesta que siguió
a mi bautizo, al arrojar mi padre desde un balcón al patio lo que llamaban "pelón",
mis primos y primas, que eran numerosos, se arrojaron sobre el montón de monedas,
mientras mi hermana Ana, segunda hermana mía, se quedaba en un rincón, mirando
el espectáculo y sin participar en él. Al preguntarle alguno por qué no entraba, ella
también, en la refriega, respondió: "Estoy esperando a que acaben". En su respuesta
veo, no tanto la tontería inocente, como la muestra de cierta cualidad insobornable (41).

La frase de Ana, "[e]stoy esperando a que acaben", no hace sentido en el contexto del juego, cuando acaben ya no habrá nada en lo que participar y tampoco habrá monedas que recoger. La misma introduce una "extrañeza inquietante" que resiste a la clausura de la lógica económica: un exceso que no responde a las reglas del juego (Freud, "Lo siniestro" 225). Sin embargo, tampoco encarna un corte radical con la partición y la repartición pautada por el juego, ni un modo de sociabilidad totalmente ajeno al interés propio, sino que guarda con ellos una relación de familiar extrañeza.

Su frase funciona en forma análoga al don que reestablece su propio enigma poniendo en cuestión la lógica en la que se inscribe. Derrida propone que "no puede

${ }^{12}$ El concepto de estructura utilizado sigue las teorizaciones de Nina Leite y Michelle Pêcheux. Ambos autores proponen la estructura como lo estable, lo repetible, lo histórico, el marco en relación al cual cobra expresión todo aquello que lo excede. Por ende, no se trata de una estructura cerrada sino abierta en relación con su propia inconsistencia. En consecuencia, el acontecimiento es inherente al concepto de estructura dado que se incluye y sólo es posible en relación a la misma; es una marca de lo Real a la que responde todo cambio en la estructura.

Revista Iberoamericana, Vol. LXXXI, Núm. 250, Enero-Marzo 2015, 315-331 ISSN 0034-9631 (Impreso)

ISSN 2154-4794 (Electrónico) 
haber don sino en el instante en que toda circulación haya sido interrumpida y a condición de ese instante" (Dar 19). Pero lejos de ser el don un nombre más para la ruptura que nos instala en el vacío, el autor propone como verdad última del don su doble atadura. Por un lado, "no hay don sin vínculo, sin obligación como recuerda Mauss", y por el otro, el don debe desvincularse de la obligación, de la deuda, del contrato y hasta del intercambio (35). En consecuencia, el don se inscribe en la circularidad temporal, espacial y económica, pero es atemporal, aespacial y aneconómico. El don se inscribe en la cadena de objetos que circulan, se dan, se truecan y se prestan, perpetuando la deuda, el cálculo y la obligación; pero se inscribe como enigma, como imposibilidad del pensamiento, como límite interno que subvierte todos los puntos de la lógica en la cual se inscribe. La respuesta de Ana funciona de manera equivalente a la infancia en la poesía de Potlatch. Torpe, fuera de lugar, inapropiada, irrisoria, tonta e inocente, aloja un pensamiento que se ha tornado extraño a sí mismo. La palabra de la infancia aloja una cualidad insobornable que bordea un punto de excepción: negación interna de la racionalidad económica en la que inevitablemente se inscribe. En Potlatch la subjetividad infantil señala el punto donde la razón encuentra su propia sinrazón, su límite interno, allí donde una "extrañeza inquietante" pone en cuestión la lógica económica que rige el intercambio (Freud, "Lo siniestro" 225).

Por ende, el don responde tanto al exceso cercano a lo irracional, como al contrato y la sujeción del vínculo con el otro. La doble atadura del don implica, por un lado, la imposibilidad del acto radical de don, y por el otro, enfrenta la demanda de don que nos interpela de la siguiente manera: "sabe tú además lo que dar quiere decir, sabe dar, sabe lo que quieres y lo que quieres decir cuando das, sabe lo que tienes intención de dar, sabe cómo se anula el don, comprométete, aunque el compromiso sea destrucción del don por el don, da, dale tú, a la economía su oportunidad" (38). La poesía de Potlatch reintroduce al don en la red de relaciones sociales en las que acontece, pero sin excluir de la misma los avatares de la intersubjetividad. Éstos responden a la imposibilidad de la sutura de sentido minada por el resto que excede el forzamiento metafórico de toda economía y todo lenguaje.

La paradoja del don recorre la poesía de Potlatch, articulando el lugar de lo contingente, lo irrepetible y "lo siniestro" en la lógica económica de acreedores y deudores. Un yo poético asociado al más pequeño, torpe al manejar los códigos culturales entorno al dinero, cómico e inapropiado subraya un resto que excede a la sutura de sentido y abre el intercambio a su propia inconsistencia. Pero la palabra de la infancia no sólo descubre a la economía como un acto de "fe, fenómeno de crédito o de confianza, de creencia y de autoridad convencional" (Derrida, Dar 32); sino que abre la posibilidad de otro sistema de crédito y de creencias en el intercambio, el cual incluye "ese oro de la no intención, el oro de no durar, de no tener, de no saber, de hacer el signo con absoluta humildad" (Carrera, Potlatch 10). De esta manera, Potlatch, pone la poesía

Revista Iberoamericana, Vol. LXXXI, Núm. 250, Enero-Marzo 2015, 315-331 ISSN 0034-9631 (Impreso)

ISSN 2154-4794 (Electrónico) 
de Carrera en relación con la creencia, con el crédito que le otorgamos al dinero, con la economía y, por ende, con la política.

\section{BiBLIOGRAFÍA}

Ávila Patricia. Prólogo. Y tú también te vas. Argentina y el dinero. Héctor Schmucler. Bueno Aires: Adriana Hidalgo, 2007.

Borges, Jorge Luis. Obras Completas. Vol. 1. Barcelona: Emencé, 1996.

Carrera, Arturo. Arturo y yo. Buenos Aires: Losada, 1980. Mi padre. Buenos Aires: Ediciones la Flor, 1985. Potlatch. Buenos Aires: Interzona editora S.A., 2004. Escrito con un nictógrafo. Buenos Aires: Interzona, 2005.

Carrera A. y Lamborghini O. El palacio de los aplausos. Rosario: Beatriz Viterbo Editora, 2002.

Derrida, Jaques. Dar el tiempo. Madrid: Tecnos, 1998 Fuerza de ley. El fundamento místico de la autoridad. Madrid: Tecnos, 1997.

Duchesne Winter, Juan. "Prólogo". La poesía de Arturo Carrera. Antología de la obra y la crítica. Juan Duchesne Winter y Nancy Fernández, eds. Pittsburgh: IILI, 2010. Fernández, Nancy. Experiencia y escritura: sobre la poesía de Arturo Carrera. Beatriz Viterbo Editora, 2008.

Freud, Sigmund. "Lo siniestro". Obras Completas. Vol. XVII. Buenos Aires: Amorrortu, 1989.

Lacan, Jacques. Escritos. T. Segovia, trad. 15ª ed. 2 vols. México: Siglo XXI, 1989. Luna, Félix. Perón y su tiempo. Buenos Aires: Editorial Sudamericana, 1984.

Argentina de Perón a Lanusse, 1943-1973. Buenos Aires: Sudamericana, 1984.

Marx, Karl. El Capital. Crítica de la economía política. Tomo 1. Buenos Aires: Cártago S.R.L., 1956.

Pacella, Cecilia. "Esquirlas de la explosión neobarroca en la poesía de los 90. La duración y el instante en La banda oscura de Alejandro de Arturo Carrera". Umbrales y catástrofes: literatura argentina de los '90. Córdoba: ediciones epoké, 2003.

Perlongher, Néstor. Poemas Completos 1980-1992. Buenos Aires: Compañía Editorial Espasa Calpe S.A./ Seix Barral, 1997.

Piccoli Hector. Si no a enhestar el oro oído. Rosario: íd, 1983.

Prieto, Martín. Breve historia de la literatura Argentina. Buenos Aires: Taurus, 2006. Rosa, Nicolás. La letra argentina crítica 1970-2002. Buenos Aires: Santiago Arcos Editor, 2003.

Romero, Luis Alberto. Argentina: una crónica total del siglo XX. Buenos Aires: Aguilar, 2000.

Sefamí, Jacobo. "Neobarrocos y modernistas en la poesía latinoamericana". Actas del XIII Congreso de la Asociación Internacional de Hispanistas. Madrid: Castalia, 1998.

Revista Iberoamericana, Vol. LXXXI, Núm. 250, Enero-Marzo 2015, 315-331 ISSN 0034-9631 (Impreso)

ISSN 2154-4794 (Electrónico) 
Seoane, María. El saqueo de la Argentina. Buenos Aires: Clacso, 2004.

Vecchio, Diego. "El despliegue del vacío: Arturo Carrera, el barroco, los orígenes". La poesía de Arturo Carrera. Antología de la obra y la crítica. Juan Duchesne Winter y Nancy Fernández, eds. Pittsburgh: IILI, 2010. 249-260.

Zizek, Slavoj. El sublime objeto de la ideología. Buenos Aires: Siglo Veintiuno Editores, 2003. 
